\title{
Yatak başı akut pankreatit şiddet indeksinin Türk toplumunda değerlendirilmesi
}

\author{
Assessment of bedside index for severity in acute pancreatitis in a Turkish population
}

Mehmet ÇELIKBILEK' ${ }^{1}$, Serkan DOĞAN², Lütfi AKYOL ${ }^{3}$, Gökmen ZARARSIZ ${ }^{4}$, Irfan URUÇ5, Haldun SELÇUK

Bozok Üniversitesi Tip Fakültesi, ${ }^{1}$ Gastroenteroloji Bilim Dalı, ${ }^{3}{ }_{\zeta ̧}$ Hastalıklan Anabilim Dall, Yozgat

Erciyes Universitesi Tip Fakültesi, ${ }^{2}$ Gastroenteroloji Bilim Dall, Kayseri

Hacettepe Universitesi Tip Fakültesi, ${ }^{4}$ Biyoistatistik Anabilim Dal, Ankara

Ordu Devlet Hastanesi, ${ }^{5}$ Gastroenteroloji Kliniği, Ordu

Başkent Üniversitesi Tip Fakültesi, ${ }^{6}$ Gastroenteroloji Bilim Dall, Ankara

Giriş ve Amaç: Akut pankreatitin erken evrelerinde şiddetli hastalığın belirlenmesi uygun tedavi yaklașımı ve iyi sonuç elde etmek için önemlidir. Bu çalışmada yatak başı akut pankreatit şiddet indeksi skorlama sisteminin Türk toplumunda hastalığın şiddetini belirlemede kullanılabilirliğinin değerlendirilmesi amaçlanmıştır. Gereç ve Yöntem: Ocak 1999 ve Aralık 2006 ylllanI arasında akut pankreatitli hastalarn bilgileri retrospektif olarak incelendi. Her hastanın yatak başı akut pankreatit şiddet indeksi, Ranson ve bilgisayarlı tomografi şiddet indeksi skorlanı hesaplandı. Hastaların klinik bilgileri, laboratuvar sonuçları, pankreatik nekroz, organ yetmezliği ve ölüm gibi bilgileri not edildi. Skorlama sistemlerinin etkinliğini karşılaştırmak için eğri altında kalan alanları (AUC) kullanıldı. Bulgular: Toplam 111 hastanın 63'ü (\%56.8) kadındı. Ortalama yaş 59.1+16.4 idi. En sık akut pankreatit etyolojisi safra kesesi taşı $(\% 57,7)$ olarak saptandı. Hastaların 23 ü $(\% 20,7)$ șiddetli pankreatit olarak değerlendirildi. Şiddetli pankreatitlerin 15 inde $(\% 65,2)$ organ yetmezliği görülürken, yedi $(\% 30,4)$ hastada pankreatik nekroz saptandı. Ölüm sadece şiddetli pankreatitli iki $(\% 8,6)$ hastada oldu. Akut pankreatitin şiddetini predikte etmede yatak başı akut pankreatit șiddet indeksi skoru Ranson ile benzer AUC değerleri verdi. Pankreatik nekrozu belirlemede yatak başı akut pankreatit şiddet indeksi skoru için AUC değeri 0,60 (0,38-0,80) bulunurken Ranson skoru için bu değer $0,70(0,48-0,87)$ olarak saptandı ve bu değerler arasında istatistiki bir farkllık bulunmadl. Pankreatik nekrozu belirlemede yatak başı akut pankreatit şiddet indeksi skoru > 2 için duyarllık, seçicilik, pozitif belirleyicilik ve negatif belirleyicilik oranları sırasıyla $\% 57, \% 69, \% 44$ ve $\% 79$ olarak saptandı. Yatak başı akut pankreatit şiddet indeksi organ yetmezliğini predikte etmede Ranson ve bilgisayarlı tomografi şiddet indeksi skorları kadar etkili bulunamadı. Sonuç: Yatak başı akut pankreatit șiddet indeksi Türk toplumunda akut pankreatitin şiddetini belirlemede kullanılabilen aynı zamanda başvurunun ilk gününde hesaplanabilecek parametrelerden oluşan ve basit olması gibi avantajları olan bir skorlamadır. Ayrica Türk popülasyonunda şiddetli akut pankreatitte pankreatik nekrozu belirlemede de kullanılabilir.

Anahtar kelimeler: Yatak başı akut pankreatit şiddet indeksi, akut pankreatit, şiddet, nekroz

\section{GİRISS}

Akut pankreatit enzimlerin aktivasyonu sonucu pankreasın inflamasyonu ile karakterize birçok klinik tabloya yol açabilen değişken seyirli bir hastalıktır. Akut pankreatit \%80-90 oranında vakada kendini sinırlayan özel bir tedavi gerektirmeyen hafif dereceli olarak görülürken, \%10-20 vakada lokal ve sistemik komplikasyonlara yol açabilen klinik olarak şid-
Background and Aims: Identification of patients at risk for severe disease early in the course of acute pancreatitis is essential to optimize management and to improve outcomes. We aimed to assess the bedside index for severity in acute pancreatitis score as a predictor of disease severity in acute pancreatitis in a Turkish population. Materials and Methods: We analyzed retrospectively acute pancreatitis patients between January 1999 and December 2006. Bedside index for severity in acute pancreatitis, Ranson and computed tomography severity index scores were calculated. Clinical data, laboratory results, pancreatic necrosis, organ failure, and mortality were registered. Accuracy of the scoring system for predicting severity was measured by the area under the receiver operating characteristic curve. Results: Of the 111 patients, 63 (56.8\%) were female. The median age was 59.1 years. Of all patients, 23 (20.7\%) had severe acute pancreatitis and $57.7 \%$ had biliary pancreatitis. Of patients with severe acute pancreatitis, 15 (65.2\%) developed organ failure, 7 (30.4\%) developed pancreatic necrosis, and 2 (8.6\%) died. Bedside index for severity in acute pancreatitis generated similar area under the receiver operating characteristic curve values to those of the Ranson score in predicting severe acute pancreatitis. The area under the receiver operating characteristic curve for the bedside index for severity in acute pancreatitis score to detect pancreatic necrosis was 0.60 (0.38-0.80) and for the Ranson score was 0.70 (0.48-0.87), with no significant differences. To predict pancreatic necrosis, a bedside index for severity in acute pancreatitis score $>2$ had a sensitivity, specificity, and positive and negative predictive values of $57 \%, 69 \%, 44 \%$, and $79 \%$, respectively. The bedside index for severity in acute pancreatitis score was not as good as Ranson and computed tomography severity index scores for predicting organ failure. Conclusions: The bedside index for severity in acute pancreatitis score was a useful method in a Turkish population for predicting the severity of acute pancreatitis, with the advantage of being simple and based on parameters obtained on the first day of hospitalization. The bedside index for severity in acute pancreatitis score is valuable in predicting pancreatic necrosis in severe acute pancreatitis in Turkish patients.

Keywords: Bedside index for severity in acute pancreatitis, acute pancreatitis, severity, necrosis

detli formda görülebilmektedir (1). Genel olarak akut pankreatitte mortalite \%2-5 olarak görülmekte ve bu oran şiddetli formunda \%20-30 olarak bildirilmektedir (1-2). Değişik serilerde akut pankreatit sonrasinda mortalite hızı \% 6-23 olarak belirtilmektedir. Morbidite ve mortaliteye yol açması nedeniyle bu hastalı̆̆ın seyrinin önceden tahmin edilmesi ve şiddetli 
hastalığın belirlenebilmesi amacıyla kullanışlı risk belirleme sistemlerinin oluşturulması tedavide önem arzetmektedir.

Ideal skorlama sistemi hızlı, güvenilir ve kolay yapılabilir olmalıdır. Günümüzde Ranson kriterleri ve bilgisayarlı tomografi şiddet indeksi (CTSI) gibi akut pankreatitin şiddetini tanımlayan skorlama sistemleri kullanılmaktadır $(3,4)$. Bununla birlikte bu skorlama sistemlerinin kendilerine özgü bir takım eksikleri mevcuttur. Wu ve arkadaşları tarafindan retrospektif olarak geliştirilen yatak başı akut pankreatit şiddet indeksi (BISAP) akut pankreatit hastalarının prognoz ve ciddiyetini belirlemeye yarayan yeni bir skorlama sistemidir (5). Daha önce birçok batı ve doğu toplumunda BISAP skorlama sisteminin uygun, kolay ve ucuz bir yöntem olarak akut pankreatitin şiddetini belirlediği onaylanmıştır (2,6-9). Türk popülasyonunda bu skorlama sisteminin kullanılabilirliği değerlendirilmemiştir. Biz burada retrospektif olarak BISAP skorlama sisteminin akut pankreatit hastalarında prognoz ve ciddiyeti belirlemede kullanılabilirliğini diğer prognostik skorlama sistemleriyle karşılaştırarak değerlendirmeyi amaçladık.

\section{GEREÇ ve YÖNTEM}

\section{Hasta popülasyonu}

Başkent Üniversitesi Hastanesi kayıtları geriye dönük olarak incelenerek 1999 ve 2006 yılları arasında akut pankreatit tanısıyla yatırılan hastaların bilgilerine ulaşıldı. Hastaların dosyaları demografik, klinik, laboratuvar ve radyolojik açıdan incelendi. Dosyalarında eksik bilgileri olan ve kronik pankreatit

\section{Tablo 1. Hafif ve şiddetli pankreatit hastalarında demografik ve laboratuvar özellikleri}

\begin{tabular}{|c|c|c|c|}
\hline Değişken & Hafif Pankreatit $(\mathrm{n}=88)$ & Şiddetli Pankreatit $(n=23)$ & $\mathrm{p}$ \\
\hline Yaş & $59,78 \pm 16,16$ & $56,70 \pm 17,48$ & 0,424 \\
\hline \multicolumn{4}{|l|}{ Cinsiyet } \\
\hline Bayan & $51(58,0)$ & $12(52,2)$ & 0,618 \\
\hline Erkek & $37(42,0)$ & $11(47,8)$ & \\
\hline \multicolumn{4}{|l|}{ Etyoloji } \\
\hline Taş & $51(58,0)$ & $13(56,5)$ & 0,872 \\
\hline Alkol & $3(3,4)$ & $0(0,0)$ & \\
\hline Post ERCP & $2(2,3)$ & $1(4,3)$ & \\
\hline Diğer & $5(5,7)$ & $1(4,3)$ & \\
\hline İdyopatik & $27(30,7)$ & $8(34,8)$ & \\
\hline \multicolumn{4}{|l|}{ Panknekroz } \\
\hline Yok & $88(100,0)$ & $16(69,6)$ & $<0,001$ \\
\hline Var & $0(0,0)$ & $7(30,4)$ & \\
\hline CTSI & $2,0(1,0-3,0)$ & $2,0(0,0-3,0)$ & 0,771 \\
\hline Ranson & $3,0(2,0-4,0)$ & $3,0(2,0-4,0)$ & 0,049 \\
\hline BISAP & $1,0(1,0-2,0)$ & $2,0(1,0-2,0)$ & 0,017 \\
\hline SIRS puanı & $1,0(1,0-2,0)$ & $2,0(1,0-2,0)$ & 0,164 \\
\hline $\log$ (Lökosit sayısı) & $4,07 \pm 0,21$ & $4,06 \pm 0,27$ & 0,905 \\
\hline Glukoz & $122,5(100,0-157,0)$ & $113,0(100,0-166,0)$ & 0,962 \\
\hline LDH & $483,0(345,5-636,0)$ & $514,0(324,0-760,0)$ & 0,719 \\
\hline AST & $80,5(33,0-164,5)$ & $34,0(18,0-141,0)$ & 0,018 \\
\hline ALT & $72,5(33,0-225,0)$ & $43,0(15,0-81,0)$ & 0,011 \\
\hline GGT & $153,5(41,0-299,5)$ & $55,0(25,0-98,0)$ & 0,001 \\
\hline AP & $203,0(171,5-301,5)$ & $237,0(123,0-369,0)$ & 0,647 \\
\hline Amilaz & $880,5(255,0-1850,0)$ & $583,0(280,0-1580,0)$ & 0,971 \\
\hline Lipaz & $1334,5(496,0-2676,0)$ & $1213,0(276,0-2173,0)$ & 0,449 \\
\hline Hematokrit & $40,98 \pm 5,51$ & $37,34 \pm 6,27$ & 0,007 \\
\hline BUN & $17,0(15,0-21,0)$ & $23,0(16,0-42,0)$ & 0,007 \\
\hline CRP & $18,9(5,0-57,0)$ & $17,2(2,0-37,6)$ & 0,207 \\
\hline $\mathrm{Ca}$ & $9,01 \pm 0,82$ & $9,03 \pm 0,87$ & 0,928 \\
\hline $\mathrm{Kr}$ & $0,9(0,7-1,1)$ & $1,1(0,8-5,0)$ & 0,006 \\
\hline Trigliserit & $91,5(74,5-125,5)$ & $95,0(80,0-134,0)$ & 0,692 \\
\hline Yatış süresi (gün) & $7,0(5,0-10,0)$ & $10,0(6,0-16,0)$ & 0,028 \\
\hline Semptom başlaması ve başvuru arası süre (gün) & $1,0(0,3-3,0)$ & $0,5(0,3-3,0)$ & 0,545 \\
\hline
\end{tabular}

Veriler sıklık (yüzde), ortalamaıstandart sapma veya ortanca (25. ve 75. yüzdelikler) olarak ifade edilmiştir. BISAP: Yatak başı akut pankreatit ciddiyet indeksi 
olarak kabul edilen hastalar çalışma dışında tutuldu. Çalışmaya abdominal bilgisayarlı tomografi (BT)'leri olan toplamda 111 hasta dâhil edildi. Çalışma protokolü Bozok Üniversitesi Klinik Araştırmalar Etik Kurulu tarafından onaylandı.

\section{Tanımlamalar}

Akut pankreatit tanısı; 1-Karakteristik karın ağrısı 2-Serum amilaz veya lipaz düzeylerinin normal üst sınırın üç katı kadar yükselmesi 3-Yapilan abdominal ultrasonografi veya BT'de akut pankreatitin bulgularını olması gibi kriterlerden iki veya daha fazlasının olması ile konuldu (10). Hastalar Atlanta klasifikasyonu kullanılarak organ yetmezliği veya lokal komplikasyonlarının olmasına göre hafif ve şiddetli pankreatit olarak iki gruba ayrıldı (10). Organ yetmezliği şok (sistolik kan basıncinın $\leq 90$ ), pulmoner yetersizlik (arteryel $\mathrm{pO}_{2}<60 \mathrm{mmHg}$ ), renal yetmezlik (serum kreatinin $>2 \mathrm{mg} / \mathrm{dl}$ ) veya gastrointestinal kanama ( 24 saatte $>500 \mathrm{ml}$ ) olarak tanımlanırken lokal komplikasyonlar pankreatik nekroz, apse ve psödokist olarak tanımlandı. Hastaların Ranson skorları ilk 48 saatteki bilgileri kullanılarak hesaplandı (3). Ranson skorları tanı anında yaş $>55$, beyaz küre sayısı $>16000 / \mathrm{ml}$, açlık kan şekeri > $200 \mathrm{mg} / \mathrm{dl}, \mathrm{LDH}>350 \mathrm{mg} / \mathrm{dl}$, AST > $250 \mathrm{IU}$ ve 48. saate hematokrit düşüşü $>\% 10$, BUN artışı $>5 \mathrm{mg} / \mathrm{dl}$, serum $\mathrm{Ca}<8 \mathrm{mg} / \mathrm{dl}, \mathrm{PaO}_{2}<60 \mathrm{mmHg}$, baz açığ $1>4 \mathrm{mEq} /$, sivı sekestrasyonu $>6$ litre kullanılarak hesaplandı. Her hastanın CTSI skorlamaları yatış sonrası çekilen abdominal BT verileri kullanılarak yapıldı (4). BT'deki görü ntüler normal görünüm (grade A, 0 puan), fokal veya diffüz pankreatik genişleme (grade B, 1 puan), peripankreatik inflamasyon veya bez anormallikleri (grade C, 2 puan), tek sivı koleksitonu (grade D, 3 puan), iki veya daha fazla sıvı koleksiyonu veya bitişik hava kabarcıklarının olması (grade E, 4 puan) olarak skorlandı. Ayrica BT'de nekrozun olmaması, \%0-30 nekroz, $\% 30-50$ nekroz, >\%50 nekroz sirasiyla 0,2,4 ve 6 puan olarak skorlandı. CTSI pankreasın görünümünden ve nekrozun büyüklüğünden elde edilen puanlar toplanarak hesaplandı.

BISAP skoru 5 parametre içermektedir; 1-BUN $>25 \mathrm{mg} / \mathrm{dl}$ 2-Mental durum bozukluğunun olması 3-Sistemik inflamatuvar yanıt sendromunun (SIRS) gelişmesi 4-Yaş > 60 olması 5-Plevral efüzyonun olması. SIRS aşağıda verilen parametrelerden iki veya daha fazlasının olması olarak tanımlandı; 1-Kalp hızı $>90 /$ dakika 2-Solunum sayısı $>20 /$ dakika veya arteryel $\mathrm{pCO}_{2}<32 \mathrm{mmHg} 3$-Vücut $1 \mathrm{sisl}<36^{\circ} \mathrm{C}$ veya $>38^{\circ} \mathrm{C} 4$-Beyaz küre sayıs $>12000 / \mathrm{ml}$ veya $<4000 / \mathrm{ml}$ (5). Hastaların BISAP skorları yatışlarının ilk 24 saatindeki veriler kullanılarak hesaplanmıştır.
Akut pankreatitli hastalarda Ranson, CTSI ve BISAP skorlarının hastalığın şiddetini belirlemedeki etkinlikleri karşılaştırıldı. Ayrıca şiddetli pankreatitlerde Ranson, CTSI ve BISAP skorlarının pankreatik nekroz, organ yetmezliği ve mortaliteyi belirlemedeki etkinlikleri karşılaştırıldı.

\section{İstatistiki analiz}

Verilerin normal dağılıma uygunluğunun değerlendirilmesinde Shapiro-Wilk testinden ve histogram, q-q grafiklerinden faydalanıldı. Gruplar arası karşılaştırmalar nicel değişkenler için bağımsız iki örneklem t testi ve Mann-Whitney U testleri ile, nitel değişkenler için kikare testleri ile değerlendirildi. Veriler sıklık (yüzde), ortalama \pm standart sapma veya ortanca (25. ve 75 . yüzdelikler) olarak ifade edildi. Şiddetli pankreatiti olan hastalarda organ yetmezliğinin ve nekrozun belirlenmesinde CTSI, Ranson ve BISAP skorlarının tanı performanslarını değerlendirmek için parametrik olmayan ROC analizleri kullanıldı ve ROC eğrileri altında kalan alanlar \%95 güven sınırları ile birlikte hesaplanarak birbirleri ile karşılaştırıldı. Daha sonra her bir skor için eşik değerleri belirlenerek duyarlılık, seçicilik, pozitif ve negatif belirleyicilik değerleri ölçümleri \%95 güven sınırları ile birlikte hesaplandı. Skorlar arası ilişkileri belirlemek üzere Spearman korelasyon analizi kullanıldı. Verilerin analizi R 3.0.0 programı ile değerlendirildi. $\mathrm{p}<0,05$ anlamlılık düzeyi kabul edildi.

\section{BULGULAR}

Çalışmaya toplam 111 hasta dahil edilmiştir. Hastaların 63'ü $(\% 56,8)$ bayan, 48'i $(\% 43,2)$ erkektir. Ortalama yaş $59,1 \pm 16,4$ 'dür. En sik akut pankreatit etyolojisi safra kesesi taşı $(\% 57,7)$ olarak saptandı. Hastaların $22^{\prime} u ̈ u(\% 20,7)$ şiddetli pankreatit olarak değerlendirildi. Şiddetli pankreatitlerin 15 'inde $(\% 65,2)$ organ yetmezliği görülürken, yedi $(\% 30,4)$ hastada pankreatik nekroz saptandı. Ölüm sadece şiddetli pankreatitli iki $(\% 8,6)$ hastada oldu. Şiddetli ve hafif pankreatitler karşılaştırıldığında yaş, cinsiyet, etyoloji açısından bir fark bulunamamıştır. Hafif ve şiddetli pankreatitlerde demografik ve laboratuvar özellikleri Tablo l'de özetlenmiştir.

Siddetli pankreatit ve hafif pankreatitler karşılaştırıldığında CTSI skorları açısından bir fark bulunamazken, şiddetli pankreatitlerde Ranson ve BISAP skorları yüksek saptandı $(p<0,05)$. Korelasyon analizleri sonucu hafif pankreatitli hastalarda Ranson skoru ile BISAP skoru arasında pozitif düzeyde, zaylf fakat anlamlı bir korelasyon tespit edildi (rho=0,367,

Tablo 2. Pankreatiti olan hastalarda hastalığın şiddetinin belirlenmesinde Ranson ve BISAP skorlarının tanı performansları

$\begin{array}{lllll}\text { Değissken } & \text { DUY (\%95 GS) } & \text { SEÇ (\%95 GS) } & \text { PBD (\%95 GS) } & \text { NBD (\%95 GS) } \\ \text { Ranson (>3) } & 0.48(0.27-0.69) & 0.73(0.62-0.82) & 0.31(0.17-0.49) & 0.84(0.74-0.92) \\ \text { BISAP (>1) } & 0.61(0.39-0.80) & 0.70(0.60-0.80) & 0.35(0.21-0.52) & 0.87(0.77-0.94)\end{array}$

DUY: Duyarllık, SEÇ: Seçicilik, PBD: Pozitif belirleyicilik değeri, NBD: Negatif belirleyicilik değeri, GS: Güven sınırı 
Tablo 3. Şiddetli pankreatiti olan hastalarda organ yetmezliğinin ve nekrozun belirlenmesinde CTSI, Ranson ve BISAP skorlarinin tanı performansları

\begin{tabular}{|c|c|c|c|c|}
\hline Değişken & DUY (\%95 GS) & SEÇ (\%95 GS) & PBD (\%95 GS) & NBD (\%95 GS) \\
\hline \multicolumn{5}{|c|}{ Organ yetmezliği } \\
\hline CTSI $(<3)$ & $0,80(0,52-0,95)$ & $0,75(0,35-0,96)$ & $0,86(0,57-0,98)$ & $0,67(0,30-0,93)$ \\
\hline Ranson $(<4)$ & $0,60(0,32-0,84)$ & $0,63(0,25-0,91)$ & $0,75(0,43-0,85)$ & $0,45(0,17-0,77)$ \\
\hline BISAP $(<2)$ & $0,33(0,12-0,62)$ & $0,50(0,16-0,84)$ & $0,56(0,21-0,86)$ & $0,29(0,08-0,58)$ \\
\hline \multicolumn{5}{|l|}{ Nekroz } \\
\hline Ranson (>3) & $0,71(0,29-0,96)$ & $0,63(0,36-0,85)$ & $0,45(0,17-0,77)$ & $0,83(0,52-0,98)$ \\
\hline BISAP $(<2)$ & $0,57(0,19-0,90)$ & $0,69(0,41-0,89)$ & $0,44(0,14-0,79)$ & $0,79(0,49-0,95)$ \\
\hline
\end{tabular}

DUY: Duyarlılı, SEÇ: Seçicilik, PBD: Pozitif belirleyicilik değeri, NBD: Negatif belirleyicilik değeri, GS: Güven sınırı

CTSI: Bilgisayarlı tomografi şiddet indeksi, BISAP: Yatak başı akut pankreatit şiddet indeksi

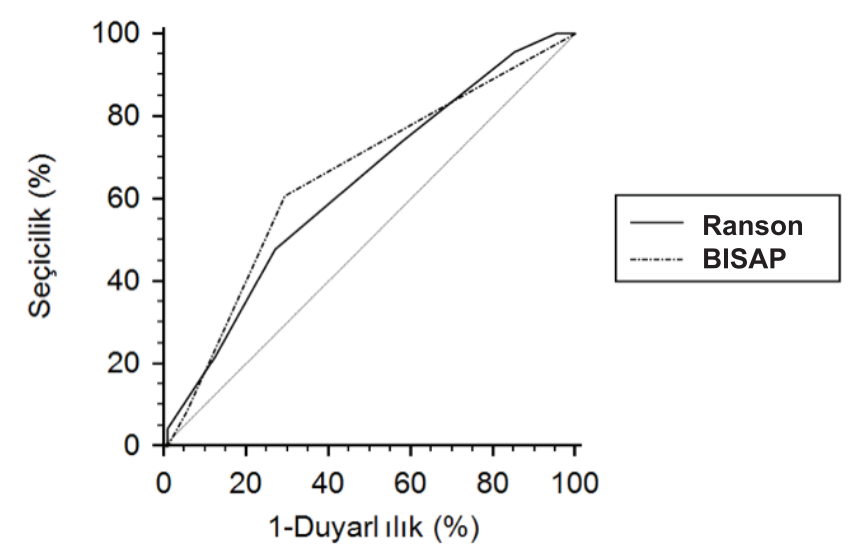

Şekil 1. Pankreatiti olan hastalarda, hastalık şiddetinin belirlenmesinde Ranson ve BISAP skorlarının tanısal performanslarının değerlendirilmesi. ROC eğrisi altında kalan alanlar ve \%95 güven sınırları sırası ile 0,63 $(0,53-$ $0,72)$ ve $0,65(0,56-0,74)$ olarak elde edildi ve ROC eğrileri altında kalan alan arasındaki farklılık istatistiksel olarak anlamlı bulunmadı ( $p>0,05)$. $\mathrm{p}<0,001)$. Her iki skor için CTSI puanı ile anlamlı bir korelasyon gözlenmedi $(p>0,05)$. Şiddetli pankreatitli hastalarda ise Ranson, BISAP ve CTSI skorları arasinda herhangi bir anlamlı korelasyon gözlenmedi ( $p>0,05)$. Şiddetli pankreatitleri predikte etmek açısından Ranson ve BISAP skorlarının eğri altında kalan alan (AUC) değerleri karşlaştırıldı. Bu değer Ranson skorunda 0,63 (0,53-0,72) çıkarken BISAP skorunda 0,65 $(0,56-0,74)$ olarak görüldü (Figür 1). Şiddetli pankreatitleri predikte etmeleri açısından her iki skor arasında bir fark bulunamadı. En iyi eşik değer Ranson için üç, BISAP için bir olarak bulundu. Ranson için bulunan bu eşik değerin şiddetli pankreatiti predikte etmesinin duyarlılık, seçicilik, pozitif belirleyicilik ve negatif belirleyicilik oranları sırasıyla \%48, $\% 73, \% 31, \% 84$ olarak bulundu. BISAP skorlama sistemi için ise sirasiyla \%61, \%70, \%35, \%87 olarak bulundu (Tablo 2).

Siddetli pankreatitin prognozunu belirlemede BISAP ve Ranson karşılaştırıldı. Şiddetli pankreatitte organ yetmezliğinin belirlenmesinde AUC değerleri karşılaştırıldığında BISAP

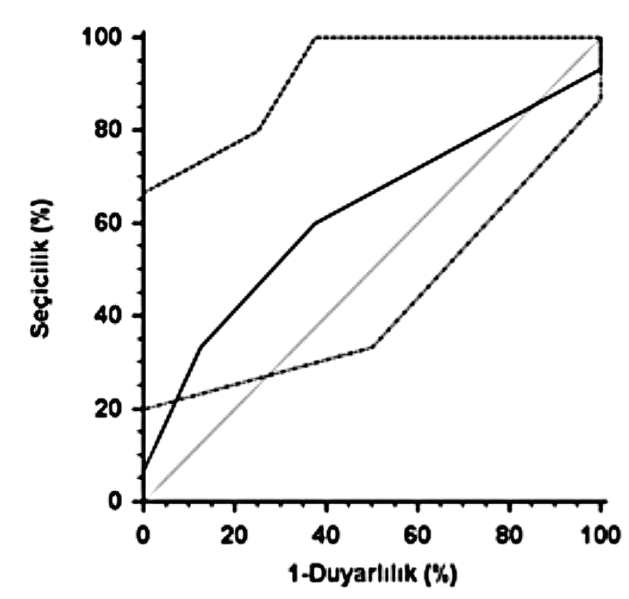

(A)

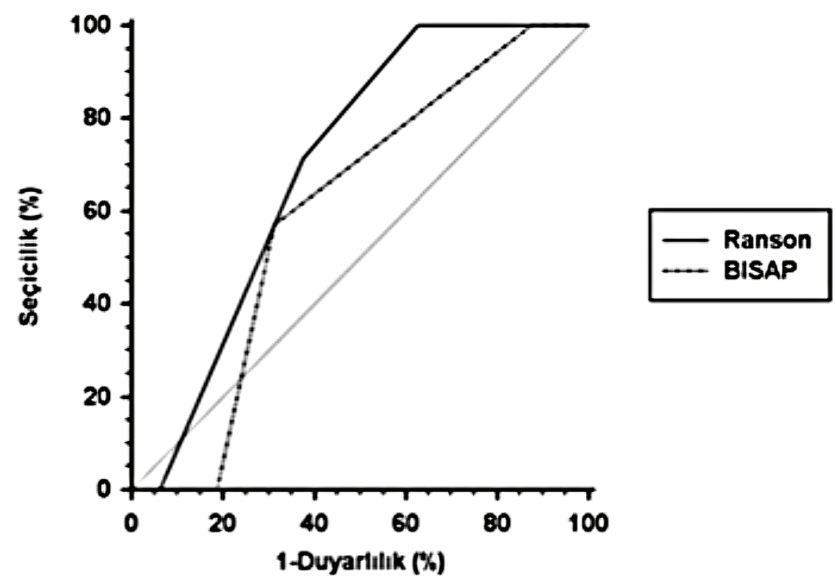

(B)

Şekil 2. (A) Ciddi pankreatiti olan hastalarda organ yetmezliğinin belirlenmesinde CTSI, Ranson ve BISAP skorlarının tanısal performanslarının değerlendirilmesi. ROC eğrisi altında kalan alanlar ve \%95 güven sınırları sırası ile $0,92(0,73-0,99), 0,62(0,40-0,81)$ ve $0,43(0,23-0,65)$ olarak elde edildi ve CTSI skoru için elde edilen ROC eğrisi altında kalan alan diğerlerine göre daha yüksek bulundu $(\mathrm{p}<0,05)$. (B) Ciddi pankreatiti olan hastalarda nekrozun belirlenmesinde Ranson ve BISAP skorlarının tanısal performanslarının değerlendirilmesi. ROC eğrisi altında kalan alanlar ve \% 95 güven sınırları sırası ile $0,70(0,48-0,87)$ ve $0,60(0,38-0,80)$ olarak elde edildi ve bu alanlar arasındaki fark istatistiksel olarak anlamlı bulunmadı $(\mathrm{p}>0,05)$. 
skoru için 0,43 $(0,23-0,65)$ değeri, Ranson skoru için 0,62 $(0,40-0,81)$, CTSI için $0,92(0,73-0,99)$ değeri elde edildi (Şekil 2-A) ve CTSI skoru için elde edilen AUC değeri diğerlerine göre daha yüksek bulundu $(\mathrm{p}<0,05)$. En uygun eşik değer BISAP skorunda iki olarak görüldü ve duyarlılık, seçicilik, pozitif belirleyicilik ve negatif belirleyicilik oranları sırasıyla \%33, \%50, \%56 ve \%29 olarak saptandı. En uygun eşik değer Ranson skorunda dört olarak görüldü ve duyarlılık, seçicilik, pozitif belirleyicilik ve negatif belirleyicilik oranları sırasıla $\% 60, \% 63$, \%75 ve \%45 olarak saptandı. En uygun eşik değer CTSI için üç olarak görüldü ve duyarlılık, seçicilik, pozitif belirleyicilik ve negatif belirleyicilik oranları sırasıla \%80, \% 75, \%86 ve \%67 olarak saptandı (Tablo 3).

Pankreatik nekrozun belirlenmesinde AUC değerleri karşılaştırıldığında BISAP skoru için 0,60 (0,38-0,80) değerleri, Ranson skoru için 0,70 $(0,48-0,87)$ değerleri elde edildi (Şekil 2-B). Bu iki değer arasında istatistiksel fark bulunamadı ( $p>0,05)$. En uygun eşik değer BISAP skorunda iki olarak görüldü ve duyarlılık, seçicilik, pozitif belirleyicilik ve negatif belirleyicilik oranları sirasıyla \%57, \%69, \%44 ve \%79 olarak saptandi. En uygun eşik değer Ranson skorunda üç olarak görüldü ve duyarlılık, seçicilik, pozitif belirleyicilik ve negatif belirleyicilik oranları sırasıyla \%71, \%63, \%45 ve \%83 olarak saptandi (Tablo 2).

Mortalite şiddetli pankreatitlerde sadece iki hastada görüldü. Sayı az olduğu için algılayıcı işletim eğrileri yapılamadı. İki hastanın da BISAP skorları iki saptandı. Hastalardan birisinin Ranson skoru beş, diğerinin dört olarak görüldü. Hastaların CTSI skorları sırasıyla sıfır ve bir olarak değerlendirildi.

\section{TARTISSMA}

Çalışmamızda akut pankreatit tanısı alan hastalar geriye dönük olarak incelenmiş ve pankreatitin şiddeti Atlanta klasifikasyonuna göre belirlenmiştir. BISAP skorunun pankreatitin şiddetini, prognozunu ve mortalitesini belirlemede kullanılabilirliği Türk toplumunda değerlendirilmiştir. Hastalığın şiddetini belirlemede BISAP skorlaması Ranson skoru ile eşdeğer bulundu. Bu çalışmada BISAP şiddetli pankreatiti belirlemede \%61 duyarlılık ile Ranson skorundan daha iyi sonuç verirken seçicilik, pozitif belirleyicilik ve negatif belirleyicilik oranları açısından Ranson ile benzer sonuçlar verdi. Ayrıca BISAP skorunda eşik değer iki alındığı zaman pankreatik nekrozu Ranson skoru ile benzer oranlarda belirleyebileceği saptandı. BISAP organ yetmezliğini belirlemede Ranson ve CTSI kadar etkili görülmedi.

Akut pankreatitin şiddeti, prognozu ve tedavi yaklaşımlarını etkilemektedir. Günümüzde birçok skorlama sistemleri akut pankreatitin şiddetini belirlemede kullanılırken, Atlanta klasifikasyonu bunların arasında geniş olarak kabul edilen ve kullanılan bir sistemdir (11-13). Atlanta klasifikasyonu, hastalığın şiddeti ve prognozuna lokal ve sistemik bulguları değerlendirerek karar veren bir sistemdir. Erken olarak uygulanamasa da pankreatitin şiddeti hakkında objektif olarak bilgi vermektedir. Bunlardan dolayı hastalığın şiddeti çalışmamızda Atlanta klasifikasyonuna göre belirlenmiştir.

Ranson skoru uzun yıllardır akut pankreatitte hastalığın şiddetini belirlemede kullanılmıştır. Genel olarak skorun üç ve üzerinde olması şiddetli hastalığı belirlemede kullanılmaktadır ve bu değerin duyarlılı̆̆ $\% 75$, özgüllüğü \%77, pozitif belirleyiciliği \%49, negatif belirleyiciliği \%91 olarak verilmiştir (1). Bizim çalışmada duyarlılık ve negatif belirleyicilik daha düşük çıkmıştır. Bu farklılık hasta seçimleri ile ilişkili olabilir. Ranson skorlamasının en önemli kısıtlılığı değerlendirmenin tamamlanması için başvuru sonrası 48 saat gerekliliğidir. Ayrıca 11 parametreden oluşmaktadır ve karmaşık olarak değerlendirilmektedir (2). CTSI tomografi görüntülerine dayanmaktadır. Lokal komplikasyonlardan yola çıkarak hesaplanmakta ve sistemik inflamatuvar cevabı yansitmamaktadır (14). BISAP akut pankreatitin şiddetini ve prognozunu belirlemeye yarayan yeni geliştirilen bir skorlama sistemidir. Ranson skorundan farklı olarak başvurunun ilk 24 saatinde değerlendirme yapabilmesi ve kolay uygulanabilir olması gibi avantajları vardır. BISAP skorlaması Ranson skorlamasından farklı olarak daha az sayıda ve kolay ulaşılabilir beş parametre kullanılarak hesaplanabilmektedir. Şunu da belirtmek gerekir ki BISAP parametrelerinden biri olan SIRS hesaplanırken dört parametreye gereksinim duyulmaktadır. Çalışmamızda BISAP; Ranson ile benzer eğri altında kalan alana, sensitivite ve spesifiteye sahiptir ve bu sonuçlar BISAP skorunun popülasyonumuzda kullanılabilir olduğunu düşündürmektedir.

Kore'den yapilan ve 289 hastanın retrospektif olarak değerlendirildiği bir çalışmada şiddetli pankreatiti belirlemede BISAP skorunun eşik değer üç için duyarlılık, seçicilik, pozitif belirleyicilik ve negatif belirleyicilik oranları sırasıyla \%45.5, \%98.9, \%76.9, \%95.8 olarak saptandı (2). Amerikadan yapılan bir çalışmada ise aynı eşik değer için bu oranlar sırasıyla \%37.5, \%92.4, 57.7\% ve \%84.3 olarak saptandı (6). Çin merkezli bir çalışmada ise en iyi eşik değer iki için bu oranlar sirasıly \%61.4, \%83.1, \%48.1, \%89.4 olarak saptandı (8). Bizim çalışmamızda en iyi eşik değer bir olarak görüldü ve bu değer için duyarlılık, seçicilik, pozitif belirleyicilik ve negatif belirleyicilik oranları sirasıyla \%61, \%70, \%35 ve \%87 saptandı. Bizim çalışmamızda önceki batı merkezli çalışmalara göre BISAP skoru için duyarlılık düşük saptanmıştır. Bunun sebebi genetik etkenler ve yaşam biçimlerindeki farklılık olabilir. Ayrıca batı merkezli çalışmalarda alkol pankreatitin en sık nedeniyken bizim çalışmamızda biliyer pankreatit daha sık görülmüştür. Çin merkezli çalışmada biliyer pankreatit ön planda görülmekte ve bu çalışmanın oranları bizim çalışmamızla benzeşmektedir. Bu oranlardaki farklılığın diğer bir nedeni de çalışmalarda kullanılan şiddetli pankreatit tanımlarındaki farklılık olabilir. 
Çalışmamızda ayrıca BISAP ve Ranson skorlarını pankreatik nekrozu predikte etmeleri açısından karşılaştırdık. Ayrıca BISAP, Ranson ve CTSI skorlarını organ yetmezliğini predikte etmeleri açısından karşılaştırdık. BISAP şiddetli pankreatitte diğer skorlama sistemlerinden prognozda organ yetmezliğini belirlemede daha az değerli görüldü. Pankreatik nekrozda ise Ranson skoru ile benzer değerler elde edildi. Çalışmamızda BISAP için pankreatik nekrozu belirleyen eşik değer iki, organ yetmezliğini belirleyen eşik değer iki olarak görüldü.

Çalışmamızın retrospektif olarak yapılması ve sadece tomografileri çekilen akut pankreatitlerin çalışmaya dahil edilmesi eksikleri olarak görülebilir. Literatürde şiddetli pankreatitlerin oranı \%10 ve \%20 olarak değişmektedir (1). Çalışmamıda şiddetli pankreatitlerin oranı \%20,7 olarak görece yüksek saptansa da literatürle uyumlu görülmektedir. Akut pankreatitte mortalite bu çalışmada \% 1,8 saptandı, şiddetli pankre- atitte bu oran \%9,5 olarak görüldü. Literatürde genel olarak bildirilen akut pankreatitte mortalite \%2-5 olarak görülmekte ve bu oran şiddetli formunda \%20-30 olarak bildirilmektedir $(1,2)$. Batı ve doğu toplumlarında yapılan çalışmalarda alkole sekonder pankreatit birinci sırada yer almaktadır. Bizim çalışmamızda mortalitede literatürden farklı rakamların çıkması bizim popülasyonumuzda bilier pankreatitlerin fazla olmasıyla ilişkilendirilebilir.

Sonuç olarak biz Türk toplumunda akut pankreatit hastalarında hastalığın şiddetini ve prognozunu belirlemede BISAP skorunu Ranson ve CTSI skorları ile karşılaştırdık. BISAP şiddetli pankreatiti ve pankreatik nekrozu belirlemede Ranson ile benzer sonuçlar göstermektedir. Ayrıca BISAP skorlamasının basit olması ve hızlı uygulanabilmesi gibi avantajları vardır. BISAP Türk toplumunda akut pankreatitin şiddetini ve prognozunu belirleyebilir.

\section{KAYNAKLAR}

1. Forsmark CE, Baillie J; AGA Institute Clinical Practice and Economics Committee; AGA Institute Governing Board. AGA Institute technical review on acute pancreatitis. Gastroenterology 2007;132:2022-44.

2. Cho YS, Kim HK, Jang EC, et al. Usefulness of the bedside index for severity in acute pancreatitis in the early prediction of severity and mortality in acute pancreatitis. Pancreas 2013;42:483-7.

3. Zeytunlu M, Akyıldız M, Tekeşin O, et al. Akut pankreatit olgularının kanıta dayalı tıp kılavuzlanı rehberliğinde incelenmesi. Akademik Gastroenteroloji Dergisi 2005;4:146-53.

4. Balthazar EJ, Robinson DL, Megibow AJ, Ranson JH. Acute pancreatitis: value of CT in establishing prognosis. Radiology 1990;174:331-6.

5. Wu BU, Johannes RS, Sun X, et al. The early prediction of mortality in acute pancreatitis: a large population-based study. Gut 2008;57:1698-703.

6. Papachristou GI, Muddana V, Yadav D, et al. Comparison of BISAP Ranson's, APACHEII and CTSI scores in predicting organ failure, complications, and mortality in acute pancreatitis. Am J Gastroenterol 2010;105:435-41.

7. Singh VK, Wu BU, Bollen TL, et al. A prospective evaluation of the bedside index for severity in acute pancreatitis score in assessing mortality and intermediate markers of severity in acute pancreatitis. Am J Gastroenterol 2009;104:966-71.

8. Chen L, Lu G, Zhou Q, et al. Evaluation of the BISAP Score in Predicting Severity and Prognoses of Acute Pancreatitis in Chinese Patients. Int Surg 2013;98:6-12.

9. Gompertz M, Fernández L, Lara I, et al. Bedside index for severity in acute pancreatitis (BISAP) score as predictor of clinical outcome in acute pancreatitis: retrospective review of 128 patients. Rev Med Chil 2012;140:977-83.

10. Bradley EL III. A clinically based classification system for acute pancreatitis: summary of the International Symposium on Acute Pancreatitis, Atlanta, Ga, September 11 through 13, 1992. Arch Surg 1993;128:586-90.

11. Bollen TL, Besselink MG, van Santvoort HC, et al. Toward an update of the Atlanta classification on acute pancreatitis: review of new and abandoned terms. Pancreas 2007;35:107-13.

12. Petrov MS, Windsor JA. Classification of the severity of acute pancreatitis: how many categories make sense? Am J Gastroenterol 2010;105:74-6.

13. Stimac D, Miletíc D, Radi'c M, et al. The role of nonenhanced magnetic resonance imaging in the early assessment of acute pancreatitis. Am J Gastroenterol 2007;102:997-1004.

14. Kaya E, Dervisoglu A, Polat C. Evaluation of diagnostic findings and scoring systems in outcome prediction in acute pancreatitis. World J Gastroenterol 2007;13:3090-4. 